\title{
Imitation Can Reduce Repetitive Behaviors and Increase Play Behaviors in Children with Autism Spectrum Disorder
}

\author{
Tiffany Field ${ }^{1,2}$, Maria Hernandez-Reif', Miguel Diego ${ }^{1,2}$, Jennifer Corbin'2, \\ Mindy Stutzman'2, Ashlee Orozco², Ava Grace², Marta Kang², Leslie Neophytou'2, \\ Kelly Russo' ${ }^{2}$, Susan Allender ${ }^{2}$, Gabriel Dominguez², Keith McGoldrick ${ }^{2}$ \\ ${ }^{1}$ Touch Research Institute, Miller School of Medicine, University of Miami, Coral Gables, USA. \\ ${ }^{2}$ Fielding Graduate University, Santa Barbara, USA \\ ${ }^{3}$ University of Alabama, Tuscaloosa, USA \\ Email: tfield@med.miami.edu
}

Received 23 June 2014; revised 18 July 2014; accepted 12 August 2014

Copyright (C) 2014 by authors and Scientific Research Publishing Inc.

This work is licensed under the Creative Commons Attribution International License (CC BY). http://creativecommons.org/licenses/by/4.0/ c) (i) Open Access

\begin{abstract}
Researchers have documented the positive effects of adult imitation on the social and joint attention behaviors of children with autism spectrum disorder. In the current study videotapes from an archival data base were recoded to address the effects of imitation on the children's stereotypic/ repetitive behavior and their behavior directed toward the adult and the toys. In the original study, the children with autism spectrum disorder $(\mathrm{N}=24)$ were videotaped in a playroom that featured 2 sets of the same toys and a seated, still-face adult for 3 minutes. This was followed by a 3-minute period of the adult imitating all of the child's behaviors/actions. Another seated, stillface adult segment followed ( $3 \mathrm{~min})$, and finally a spontaneous play period $(3 \mathrm{~min})$. During the second still-face following the imitation period versus the first still-face period, the children spent more time touching the adult, and touching and playing with the toys. During the imitation versus the spontaneous play session the children showed less stereotypic/repetitive behavior including less time bringing the toys to the face and making autistic-like sounds. These data suggest that imitation by the adult led to less stereotypic/repetitive behavior by the children with autism spectrum disorder and more engaging behavior including both touching the adult and touching and playing with the toys.
\end{abstract}

\section{Keywords}

Children with Autism Spectrum Disorder, Imitation, Stereotypic/Repetitive Behaviors

How to cite this paper: Field, T., Hernandez-Reif, M., Diego, M., Corbin, J., Stutzman, M., Orozco, A., Grace, A., Kang, M., Neophytou, L., Russo, K., Allender, S., Dominguez, G. \& McGoldrick, K. (2014). Imitation Can Reduce Repetitive Behaviors and Increase Play Behaviors in Children with Autism Spectrum Disorder. Psychology, 5, 1463-1467.

http://dx.doi.org/10.4236/psych.2014.512157 


\section{Introduction}

Imitation by adults can facilitate social behaviors in children with autism spectrum disorder including their attention and imitation skills (Ezell et al., 2010; Field, et al., 2013; Ingersoll \& Shreibman, 2006). In the Ingersoll and Schreibman (2006) study, teaching reciprocal imitation skills to young children with autism increased their imitation skills and their imitative behavior in other situations. And, in the Field et al. (2013) study, reciprocal imitation was noted in the children with autism during imitative play sessions. Other social communication behaviors have increased in these children following adult imitation including joint attention (Ezell et al., 2010; Ingersoll, 2012) and creative toy play (Cardon \& Wilcox, 2011; Katagiri, Inada, \& Kamio, 2010).

In the present study archival videotapes from earlier research by our group (Field, Field, Sanders, \& Nadel, 2001) were recoded to determine whether children with autism might show less stereotypic/repetitive behavior during play sessions with an adult who imitated the children's behaviors versus spontaneous play sessions when they were not imitating the children's behaviors (Field, et al., 2001). A second question was how the children related to the imitative adult and toys during a still-face situation that followed versus preceded an imitation session. In the Field et al. (2001) study, the play sessions started with an adult still-face condition followed by a play session in which the adult was either imitative or contingently responsive. This segment, in turn, was followed by a second still-face condition and a subsequent spontaneous play condition. The group of children who were playing with an imitative adult researcher versus the group playing with a contingently responding adult researcher showed more distal social behaviors (looking at the adult, smiling and vocalizing) and more proximal social behaviors (approaching and touching the adult). These adult imitation effects were later replicated by Heimann, Laberg, and Nordoen (2006). But the children's stereotypic/repetitive play behaviors were not coded in these studies, and the still-face segments were not included in the coding. Thus, for the current study, videotapes from the Field et al. (2001) study were recoded to assess the effects of adult imitation on 1) the behaviors directed toward the adult and toys during the still-face session that followed versus preceded the imitation session; and 2) the stereotyped/repetitive behaviors during the imitation versus the spontaneous play sessions.

\section{Method}

\subsection{Participants}

The sample that was videotaped for the original study included twenty-four preschool children with autism (12 boys and 12 girls), and they ranged from 4 to 6 years of age $(M=5.4)$.They were middle socio-economic status (Hollingshead Index, $M=2.9$ ). All children had received a DSM-IV diagnosis of autism that was confirmed by a clinical psychologist at the children's school. The children's Psychoeducational Profile Revised (PEP-R) scores averaged 18.8 (imitation $=17.9$, perception $=22.6$, cognitive performance $=18.2$ and cognitive verbal $=16.7$ ), and there was very little variability within the sample, suggesting that this was a homogeneously low-performing group of children. In addition, all of the children were classified as non-verbal based on the diagnostic assessment.

\subsection{Original and Current Study Procedures}

Following the Institution Review Board's approval of the original study, the parents gave informed consent for their children to be videotaped and for the researchers to code the videotapes. The interaction sessions were held in a play room equipped with two chairs, a table and two identical sets of toys to enable imitation of same object actions. Placed in full view on the table, the two sets of toys included cups, plates, slinkies, dolls, balls, hats, sunglasses, umbrellas, stuffed animals and balloons. The child was brought into the room by a teacher for the following play segments which were each 3 minutes duration: 1) the adult seated and still-face; 2) the adult imitating all of the child's behaviors/actions; 3) the adult seated and still-face; and 4) the adult spontaneously interacting with the child. These sessions were videotaped, and for the purposes of the present study, the videotapes were recoded for: 1 ) behaviors directed toward the adult and toward the toys during the two still-face conditions, the one preceding and the one following the imitation segments; and 2) stereotypic/repetitive behaviors during the imitation versus the spontaneous play conditions.

\subsection{Coding for the Current Study}

The child behaviors that were coded during the two still-face conditions included the following: 1) looking at, sitting next to and touching the adult; 2) wandering around the room; and 3) looking at, touching and playing 
with the objects. The child behaviors that were coded during the imitation and spontaneous play segments included the following: 1 ) repetitive body actions; 2 ) repetitive movements with the toys; 3 ) bringing the toys to the face; and 4) autistic-like sounds.

Ten graduate students were trained to code the videotapes that were randomly assigned to them. The coders were blind to the purpose of the study. Inter-coder reliability on the individual behaviors was established by Cohen's Kappas on one-third of the videotapes and ranged from 0.79 to $0.91(\mathrm{M}=0.84)$. The videotapes of the adult and child were coded at 10-second time intervals for the 3-minute phases, with the coder checking the child and adult behaviors on a time sample unit coding sheet whenever the behaviors occurred. The total number of time sample units checked for each behavior was divided by the total number of time sample units to calculate the percent time that each behavior occurred for each interaction phase (first still-face, imitation, second still-face, spontaneous play). Percent time was calculated because the length of the interaction periods varied by a few seconds.

\section{Results}

Repeated measures analyses of variance (ANOVAs) were conducted on: 1) the group of adult-oriented and the toy-oriented play behaviors of the children during the still-face condition following versus preceding the imitation segment; and 2) the stereotypic/repetitive behaviors of the children during the imitation versus the spontaneous play segments.

As can be seen in Table 1, during the still-face period following the imitation period versus preceding the imitation period the children spent more time: 1) touching the still-face adult; 2) touching the toys; and 3) playing with the toys.

As can be seen in Table 2, during the imitation versus the spontaneous play periods, the children spent: 1) more time in body movements; and 2) less time in stereotypic/repetitive movements including bringing toys to the face and repetitive autistic-like vocalizations.

\section{Discussion}

Just as imitation of the behaviors of children with autism has increased their joint attention (Ezell et al., 2010),

Table 1. Means for \% time behaviors occurred for the first and second still-face play segments.

\begin{tabular}{cccc}
\hline Behavior & Still-face 1 & Still-face 2 & F value \\
\hline Looking at adult & 36.2 & 29.4 & N.S. \\
Sitting next to adult & 26.1 & 26.7 & N.S. \\
Touching adult & 6.0 & 9.5 & $5.31^{1}$ \\
Wandering around & 20.8 & 15.3 & $4.25^{1}$ \\
Looking at objects & 61.2 & 55.7 & N.S. \\
Touching objects & 52.3 & 60.8 & $4.12^{1}$ \\
Playing with objects & 48.4 & 66.9 & $6.27^{2}$ \\
\hline${ }^{1} p<0.05,{ }^{2} p<0.01$. & & &
\end{tabular}

Table 2. Means for \% time behaviors occurred during imitation and spontaneous play segments.

\begin{tabular}{cccc}
\hline Behavior & Imitation & Spontaneous play & F value \\
\hline Body movements & 39.8 & 39.8 & $11.02^{1}$ \\
Moving objects & 32.7 & 40.4 & N.S. \\
Repetitive objects-to-face & 6.3 & 16.8 & $14.06^{2}$ \\
$\begin{array}{c}\text { Repetitive autistic-like } \\
\text { vocalizations }\end{array}$ & 6.7 & 24.4 & $16.32^{2}$ \\
\hline
\end{tabular}

${ }^{1} p<0.05,{ }^{2} p<0.01$. 
and imitation behavior (Field et al., 2013), it also reduced stereotypic/repetitive behavior of the children in this study. Although stereotypic/repetitive behaviors in children with autism can interfere with their social interactions, very little research has been conducted on the imitation effects on those behaviors. Most of the research has focused on the effects of adult imitation on the children's social communication behaviors such as looking, smiling and touching (Field et al., 2001), on imitation behaviors (Ingersoll \& Shreibman, 2006) and on joint attention behaviors (Ezell et al., 2010). In this study, imitation of the children's behaviors by the adult not only led to fewer stereotypic/repetitive behaviors by the children but also more engaging/exploratory behaviors with the still-face adult and with the toys in the playroom.

The children's more frequent relating to the play toys ( $48 \%$ - 67\% time) than the adult (6\% - 36\% time) during the still-face condition was not surprising given the stillness of the adult. Nonetheless, the children spent a third of their time looking at the still-face adult and sitting next to the adult and even $6 \%-10 \%$ time touching the adult, suggesting that they were trying to communicate with the adult even though she was still-face and a stranger. The touching the adult appeared to be an attempt to re-engage the adult during the second still-face after the imitation session when the children touched the still-face adult more often. The greater amount of touching and playing with the toys during the second versus the first still-face could relate to the greater familiarity of the toys 6 minutes into the play session and especially following the imitation period during which the adult and the child used the same toys during their rounds of reciprocal imitation, much as occurred in our earlier study (Field et al., 2013). Imitation also led to the initiation of novel actions with objects in that study and to creative toy play in others' studies (Cardon \& Wilcox, 2011; Katagiri et al., 2010).

The comparisons between the behaviors of the children during the imitation versus the spontaneous play sessions revealed more body movements time during the imitation session and less time bringing toys to the face and less time uttering repetitive autistic-like sounds. The greater time that body movements were observed was not surprising inasmuch as most of the reciprocal imitation involved large body movements through space using the larger toys, e.g. the balloons and umbrellas, as has been reported previously (Field et al., 2001; Nadel, et al., 2006). The less frequent bringing toys to the face may also relate to the predominant use of the larger toys during the rounds of reciprocal imitation (Field et al., 2013).

The effects of imitation on stereotypic/repetitive behaviors like the bringing the toys to the face behavior and the autistic-like sounds have not been assessed in imitation studies. Some have interpreted these stereotypic behaviors as self-stimulation (Vivanti, Trembath, \& Dissanayake, 2014; Zachor \& Ben-Itzchak, 2014). Body movements may have occurred more often during imitation versus spontaneous play ( 3 times as often) because the imitation sessions may have been more stimulating and thereby less conducive to self-stimulation.

Limitations of this study include not having a control group of similar developmental age to determine the degree to which these behaviors differ in the children with autism. Further, because of the limited range of the children's PEP-Rscores, we could not assess relationships between the children's developmental levels and their behaviors. Also, these data may not generalize beyond this age group or apply to children with other developmental disabilities or language development delays. Nonetheless, the results of this study suggest that an adult's imitative behavior can reduce stereotypic/repetitive behaviors of preschoolers with autism and can facilitate their social behaviors and toy play behaviors.

The most novel findings of this study were that the adult's imitative behavior led to decreased stereotypic/ repetitive behavior of the children during the imitation periods and that they showed more engaging behavior (touching) the stranger still-face adult following the imitation segment and more touching and playing with the playroom toys. Imitating non-verbal, low-functioning preschoolers with autism during play may be an effective intervention for decreasing their stereotypic/repetitive behaviors and for increasing their proximal (touching) behavior with adults and their play behavior with toys.

\section{Acknowledgements}

We wish to thank the children who participated in this study and Johnson and Johnson Pediatric Institute for their funding.

\section{References}

Cardon, T. A., \& Wilcox, M. J. (2011). Promoting Imitation in Young Children with Autism: A Comparison of Reciprocal Imitation Training and Video Modeling. Journal of Autism and Developmental Disorders, 41, 654-66. 
http://dx.doi.org/10.1007/s10803-010-1086-8

Ezell, S., Field, T., Nadel, J., Newton, R., \& Murrey, G. (2012). Imitation Effects on Joint Attention Behaviors of Children with Autism. Psychology, 3, 681-685. http://dx.doi.org/10.4236/psych.2012.39103

Field, T., Field, T., Sanders, C., \& Nadel, J. (2001). Children with Autism Displaymore Social Behaviors after Repeated Imitation Sessions. Autism1, 5, 317-323. http://dx.doi.org/10.1177/1362361301005003008

Field, T., Ezell, S., Faut, J. L., Grace, A., Allender, S., \& Siddalingappa, V. (2013). Reciprocal Imitation Following Adult Imitation of Children with Autism. Infant and Child Development, 22, 642-648. http://dx.doi.org/10.1002/icd.1812

Heimann, M., Laberg, K. E., \& Nordeen, B. (2006). Imitative Interaction Increases Social Interest and Elicits Imitation in Non-Verbal Children with Autism. Infant and Child Development, 15, 297-309. http://dx.doi.org/10.1002/icd.463

Ingersoll, B. (2012). Brief Report: Effect of a Focused Imitation Intervention Nonsocial Functioning in Children with Autism. Journal of Autism and Developmental Disorders, 42, 1768-1773. http://dx.doi.org/10.1007/s10803-011-1423-6

Ingersoll, B., \& Schreibman, L. (2006). Teaching Reciprocal Imitation Skills to Young Children with Autism Using a Naturalistic Behavioral Approach: Effects on Language, Pretend Play, and Joint Attention. Journal of Autism and Developmental Disorders, 36, 487-505. http://dx.doi.org/10.1007/s10803-006-0089-y

Katagiri, M., Inada, N., \& Kamio, Y. (2010). Mirroring Effect in 2- and 3-Year-Olds with Autism Spectrum Disorder. Research in Autism Spectrum Disorders, 4, 474-478. http://dx.doi.org/10.1016/j.rasd.2009.11.004

Nadel, J. (2006). Does Imitation Matter to Children with Autism? In S. Rogers, \& H. G. Williams (Eds.), Imitation and the Social Mind: Autism and Typicaldevelopment (pp. 118-137). New York, NY: Guilford Press.

Vivanti, G., Trembath, D., \& Dissanayake, C. (2014). Mechanisms of Imitation Impairment in Autism Spectrum Disorder. Journal of Abnormal Child Psychology. (Epub ahead of print) http://dx.doi.org/10.1007/s10802-014-9874-9

Zachor, D. A., \& Ben-Itzchak, E. (2014). The Relationship between Clinical Presentation and Unusual Sensory Interests in Autism Spectrum Disorders: A Preliminary Investigation. Journal of Autism and Developmental Disorders, 44, 229-235. http://dx.doi.org/10.1007/s10803-013-1867-y 
Scientific Research Publishing (SCIRP) is one of the largest Open Access journal publishers. It is currently publishing more than 200 open access, online, peer-reviewed journals covering a wide range of academic disciplines. SCIRP serves the worldwide academic communities and contributes to the progress and application of science with its publication.

Other selected journals from SCIRP are listed as below. Submit your manuscript to us via either submit@scirp.org or Online Submission Portal.
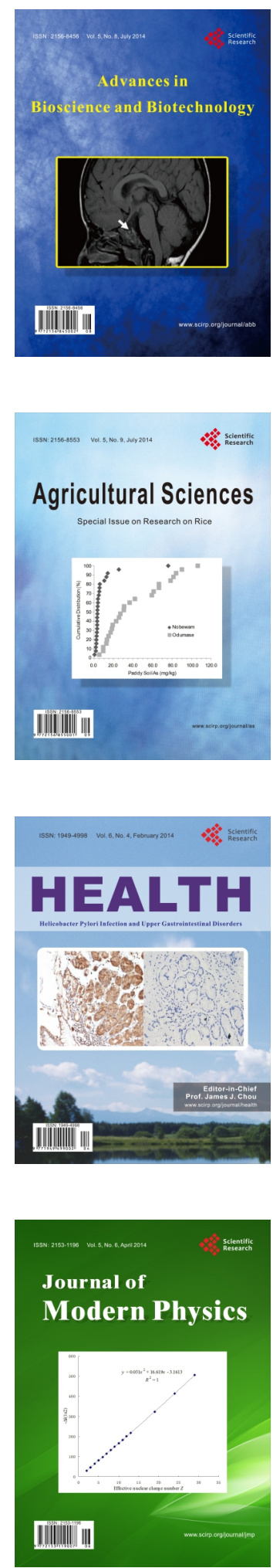
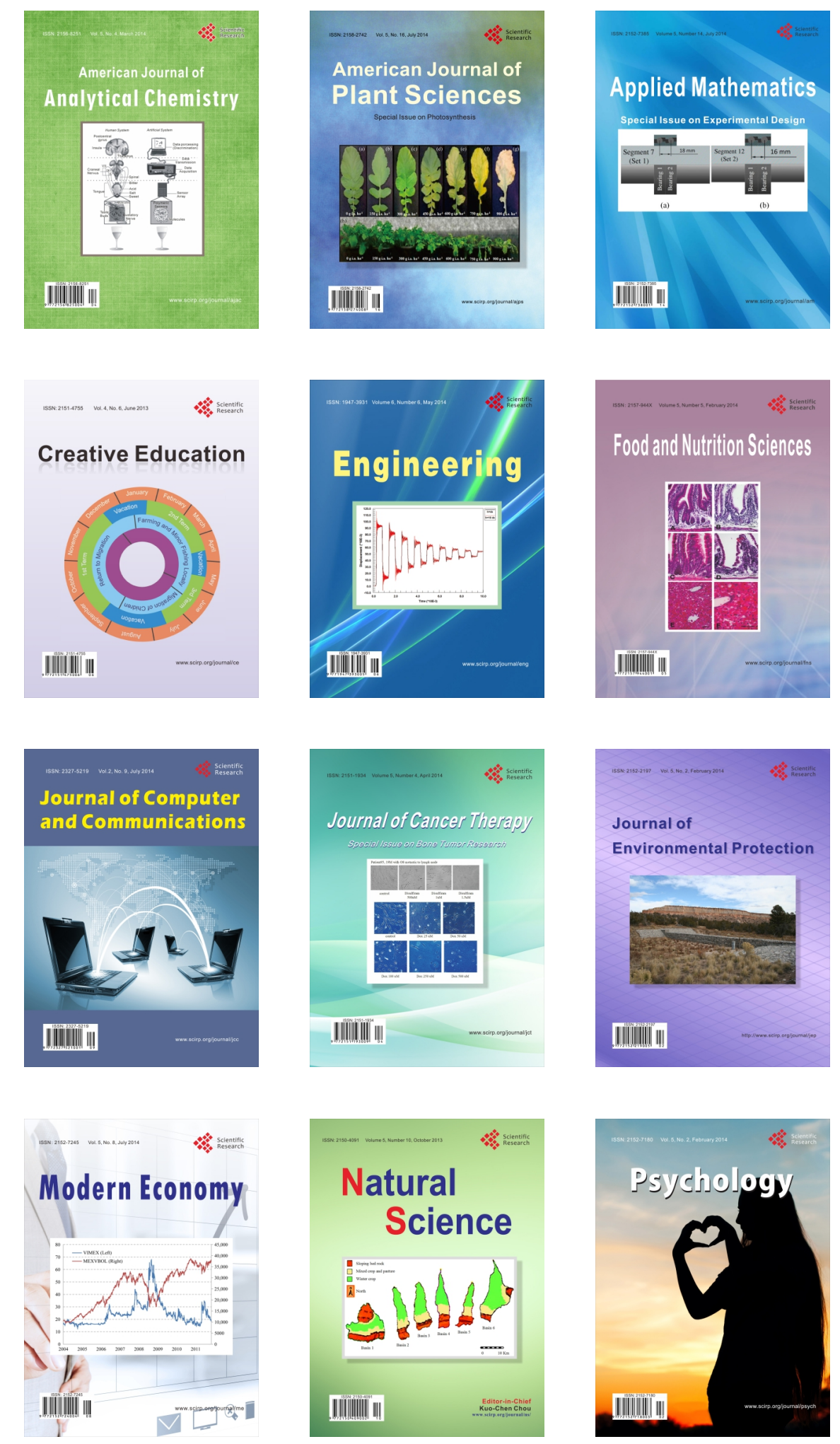